\title{
Exploring deep potential aquifer in water scarce crystalline rocks
}

\author{
Subash Chandra*, E Nagaiah, D V Reddy, V Ananda Rao and Shakeel Ahmed \\ CSIR - National Geophysical Research Institute, Uppal Road, Hyderabad 500 007, Andhra Pradesh, India. \\ ${ }^{*}$ Corresponding author.e-mail: schandra75@gmail.com chandra_s75@ngri.res.in
}

\begin{abstract}
Characterization of the shear zone with pole-pole electrical resistivity tomography (ERT) was carried out to explore deep groundwater potential zone in a water scarce granitic area. As existing field conditions does not always allow to plant the remote electrodes at sufficiently far of distance, the effect of insufficient distance of remote electrodes on apparent resistivity measurement was studied and shown that the transverse pole-pole array affects less compared to the collinear pole-pole array. Correction factor have been computed for transverse pole-pole array for various positions of the remote electrodes. The above results helped in exploring deep aquifer site, where a $270 \mathrm{~m}$ deep well was drilled. Temporal hydro-chemical samples collected during the pumping indicated the hydraulic connectivity between the demarcated groundwater potential fractures. Incorporating all the information derived from different investigations, a subsurface model was synthetically simulated and generated 2D electrical resistivity response for different arrays and compared with the field responses to further validate the geoelectrical response of deep aquifer set-up associated with lineament.
\end{abstract}

\section{Introduction}

Water scarcity is a well known problem in India particularly in the hard rock terrain of semiarid climatic condition, where groundwater level has considerably declined due to over-exploitation and irregular rainfall. Existing bore-wells $(\sim 60 \mathrm{~m}$ deep) in Andhra Pradesh are not yielding enough water to fulfill the requirement (Rao et al. 2008). TERI's report (2003) brings astonishing details on the existing as well as the impending water crisis in India. The investigation presents the declining trend of water storage since 1947 to 1997 and projects a dismal scenario of India by 2047 . The annual per capita water availability in India fell by $62 \%$ in the first 50 years of independence and the trend may likely to worsen in the next 50 years with a projected $67 \%$ decline. The underground reservoirs are expected to dry by 2025 in as many as 15 states in India, if the present level of exploitation and misuse of underground water continues. Decision support tool developed in granitic terrain of Mahaeshwram watershed in southern India projected that $50 \%$ of the existing wells go dry in few years causing serious socio-economic consequences, if the present trend of groundwater exploitation continues. Hence it was suggested for change in the cropping pattern as well as artificial groundwater recharge (Dewandel et al. 2007). Though the groundwater is replenishable due to rainfall, the imbalance between recharge and pumping is widening due to increasing population

Keywords. Geophysics; collinear and transverse pole-pole array; groundwater resources; deep potential aquifer; fracture zone; granite. 
associated with high agriculture activity based on the groundwater.

The entire hydrogeological set-up in the hard rock region can be divided into two distinct groundwater systems. One at shallow depth usually lies in unconfined conditions with a local recharge and dense pumping structures. This system of aquifer is vulnerable to both for water scarcity as well as contamination. The other one is at comparatively deeper depth in confined or semi-confined conditions with recharge source at a longer distance and comparatively less groundwater withdrawal. Such a system is less vulnerable compared to shallow one. Hence there is a need to explore the deep groundwater potential fracture zones to meet the present demand.

A decade back, depth to groundwater was very shallow, and exists in the weathered/laminated portion of the hard rock areas. However, due to the mounting stress on the groundwater system, water levels declined to the fissured zone. Even the deeper wells also turns dry due to limited potential of fracture system and extensive development. The fissured/fractured zone lying or connected with lineament still have better chances of supplying the water even during the pre-monsoon period (Chandra et al. 2006a, 2010). As density of fracture reduces with depth, exploration of deep fractures becomes a challenging task. The volumetric contribution of the deeper fracture to the total signal measured at surface become insignificant.

In general, the characteristic features of granitic aquifers that are found in the southern Indian peninsula revealed that potential aquifers can be found up to a depth of around $60 \mathrm{~m}$ from the surface except rarely captured deep fractures of the tectonic origin. Chandra et al. (2010) explored $>60 \mathrm{~m}$ deep high yielding wells associated with the quartz reef in granite host rock. Such features are mostly one dimensional and quite difficult to delineate using surface geophysical techniques. This paper presents an approach adopted to explore deep fracture systems associated with potential groundwater zone, in a water scarce granitic terrain located at APSP campus, Dichpally, Nizamabad district in India (figure 1). This study was done to provide water to approximately 1500 people belonging to the Andhra Pradesh Special Police (APSP), 7th Batallian, Dichpally, Nizamabad.

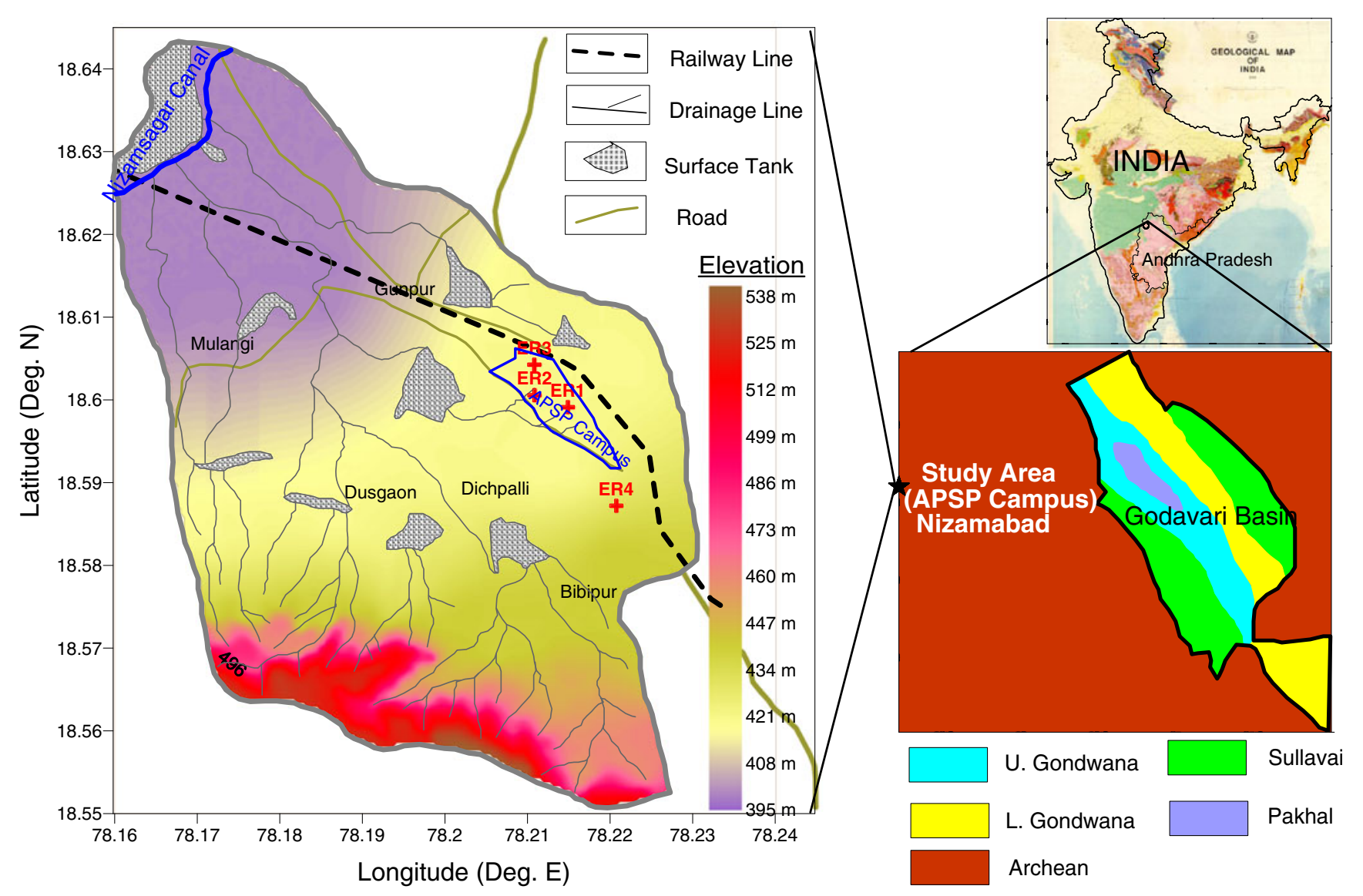

Figure 1. Location map of APSP campus, Dichpally, Nizamabad (India). 


\section{Study area}

APSP campus is located in Dichpally village of Nizamabad district (i.e., $\sim 135 \mathrm{~km} \mathrm{NNW}$ of Hyderabad) in Andhra Pradesh covering $19^{\circ}-$ $20^{\circ} \mathrm{N}$ and $77^{\circ}-79^{\circ} \mathrm{E}$ (figure 1 ). The shallow aquifer system is having limited groundwater potential and almost meager groundwater available during summer months. The area is covered by peninsular gneissic complex, which includes various litho-units, mainly granites and gneisses with numerous enclaves of older metamorphic rocks of diverse mineralogy (Dubbak 1990; Perraju and Natarajan 1977; Rao et al. 2008). Several proterozoic dolerite dykes and also quartz intrusions are seen in the area trending in $\mathrm{N}-\mathrm{S}$ direction. Cretaceous basalts are covered in the south-west and south-eastern parts.

The study area is the south-western fringe zone of a major lineament called Godavari rift valley running NW-SE direction. The multi-stage developed Godavari rift valley created several weak zones/faults in basement rock at their respective boundaries (Sarma and Rao 2005). These weak zones are potential zones for groundwater occurrence. Geophysical methods are used to identify these weak zones in order to explore deep groundwater potential zones.

\section{Hard rock aquifer characteristics}

Groundwater resources in crystalline rocks such as granites, gneisses and schists is mainly restricted to weathered and to some extent to the fracture zones. Due to high heterogeneity in the hard rock, especially in terms of fracture system, the aquifer characteristics vary from place to place and therefore the water holding capacity of these rocks also vary drastically in space (Chandra et al. 2006a, 2008). In hard rock regions, groundwater occurs mainly at the top in weathered/laminated granite and other pore spaces found in the form of cracks, joints and fractures developed as a result of some geological process. Weathering and fissuring are interlinked processes. For example, biotite in granite is relatively more susceptible to weathering when it comes in to contact with moisture (Eggler et al. 1969; Ledger and Rowe 1980) and the resultant swelling increase the volume favouring the development of cracks and fissures (Dewandel et al. 2006). However, there are other types of fractures generated due to tectonic activities, which are supposed to be extended to a large distance horizontally as well as sub-vertically which favour the groundwater movement (Sukhija et al. 2006). Fissuring is mostly controlled by geomorphology of the area and thus their extension may not be very large. Whereas, the tectonic fractures may be of large dimension based on the strength of the tectonic activity.

Wyns et al. (2004) have given a simplified geological model describing various litho units in hard rocks (figure 2). The units are described from top to bottom as: (i) saprolite or regolith, derived from prolonged in situ decomposition of bed rock with a thickness varying from negligible, where eroded to few tens of meters. The base of the saprolite is frequently laminated, constituted by a relatively consolidated weathered parent rock (Eswaran and Bin 1978; Acworth 1987; Sharma and Rajamani 2000; Chigira 2001; Dewandel et al. 2006), (ii) fissured layer consists of dense horizontal, sub-horizontal and sub-vertical fissures (Houston and Lewis 1988; Howard et al. 1992; Maréchal et al. 2003; Wyns et al. 2004), and then (iii) compact bedrock, that may locally exhibit tectonic fracturing. The fissured layer is generally characterized by two sets of fissures like sub-horizontal and sub-vertical, where density decreases with depth (Houston and Lewis 1988; Howard et al. 1992; Dewandel et al. 2006; Chandra et al. 2008) and assume the transmissive function of the composite aquifer. The lithological

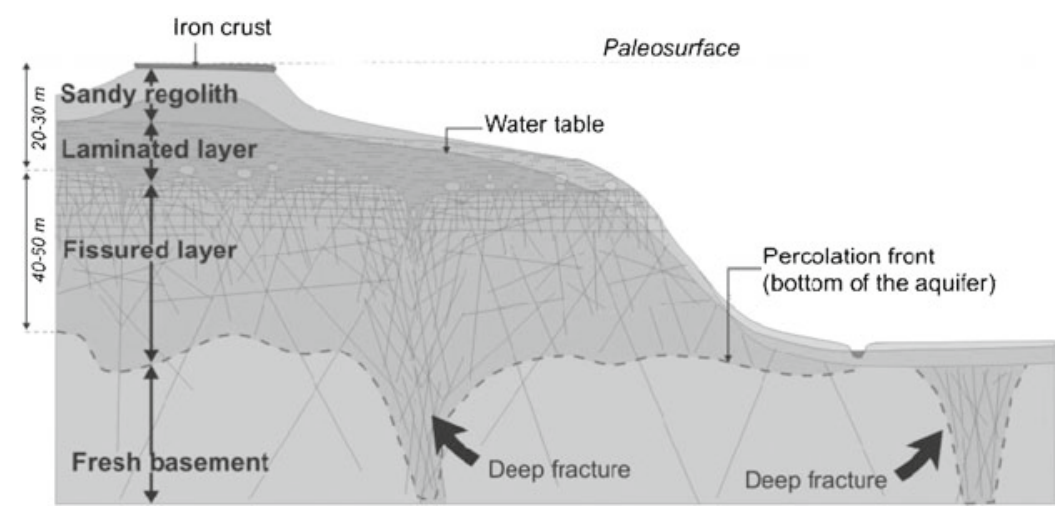

Figure 2. Simplified geological weathering profile of hard rock aquifer (after Wyns et al. 2004). 
model shows dominance of lateral fracture over vertical, which is probably the characteristic property of the hard rock generated due to fissuring; however, the deeper fractures could be generated due to tectonic activity.

With the consequence of groundwater overexploitation, water level is receding annually and thus, at present, confined to fissured/fractured zones. Groundwater movement in the fractured/ fissured zone is dependent on the fracture network. Therefore, this zone is also called as semi-confined aquifer as water struck while drilling at deeper level rises upward to maintain the hydraulic and atmospheric pressure balance.

\section{Methodologies used}

Referring to Wyns et al.'s (2004) lithological model of hard rock, it was planned to explore the deep fractured granite associated with lineament that may qualify into potential aquifer. Thus, Shuttle Radar Topographic Mission (SRTM) data as well as geological map of the area were studied to prepare lineament map followed by field ground surveys. Four ERT profiles with WennerSchlumberger array were carried out first to confirm the existence of lineament in the field followed by deep characterization by pole-pole ERT. To overcome the practical problem of insufficient distance for remote electrodes, these were planted in transverse direction of the profile and correction factor (to be multiplied with the measured apparent resistivity data before its inversion for true resistivity) was computed for the existing field condition. Based on the ERT results, a site was selected and drilled to cross-check the ERT results and also to understand the hard rock complexity. Temporal hydro-chemical data were analyzed to find out the interconnectivity of the observed fractures. Hydraulic conductivity for different zones has been estimated from electrical resistivity parameters. To have a cross validation of all the geophysical results, synthetic simulation has been carried out to generate $2 \mathrm{D}$ electrical resistivity response of shear zone across profile.

\section{Results and discussions}

\subsection{Geomorphology}

It is quite evident from the earlier studies that lineaments play a vital role in exploring the groundwater potential sites (Lattman and Parizek 1964; Mabee et al. 1994; Magowe and Carr 1999; Chandra et al. 2006a; Solomon and Quiel 2006). Field studies were carried out to map the lineament pattern in the study area using the Shuttle Radar
Topographic Mission (SRTM) images, remote sensing data of Landsat image of ETM+2000 (Path-144 and Row-47 form USGS website www.landsat.org). Visual interpretation of the SRTM data, revealed cluster of regional lineaments within the basement rock trending in different directions such as NW-SE, NNW-SSE, NNE-SSW and NE-SW (figure $3 \mathrm{a}, \mathrm{b}$ ). The NW-SE lineaments are predominant in the region running hundreds of kilometers.

The geological map of Nizamabad district obtained from Geological Survey of India (1995) has also been studied for structural interpretation of the study area around Dichpally (figure 3c, d). It has also revealed similar features, i.e., there are three sets of lineaments trending in NW-SE and NE-SW and N-S to NNE-SSW directions. The major lineaments of NW-SE are cross-cut by NE-SW lineaments. The NW-SE trend resembles a major deformed zone, which acts as a shear zone and other directions of lineaments could be fractures resulting from the shear zone. Deccan basaltic flows are also covered in the surface area in the south of Dichpally. The major NW-SE lineament running from Dichpally joins Godavari river, oriented in the east-west direction locally. Several dolerite dykes with varying length (few meters to several kilometers) and width $(10-50 \mathrm{~m})$ are also seen traversing $\mathrm{N}-\mathrm{S}$ direction passing east of Dichpally (figure 3c, d). But majority of dykes are running in NE-SW direction located at the southern portion.

Field observations reveal that the tonalities and younger granites have undergone brittle to ductile deformation at several places. Phyllonitic nature and shear zone imprints of small scale arcuate patterns found in the basement tonalities at Dusgaon village represent NW-SE ductile shearing. Grey to pink porphyritic granites of younger intrusions in basement tonalities were observed at several places. The fractures in the granites have been intruded by number of thin quartz veins that may interrupt the groundwater movement.

\subsection{Electrical resistivity}

Having wide range of resistivity for different geological materials, electrical methods are the first preference for the various hydrogeological problems (Keller and Frischknecht 1966; Kelly and Frohlich 1985; Singhal et al. 1998; Barker et al. 2001; Jain et al. 2003; Chand et al. 2004; Rao and Chandra 2005; Krishnamurthy et al. 2006; Chandra et al. 2006b,c, 2010; Dhakate et al. 2008). Vertical electrical sounding by Schlumberger array is the most commonly employed method to demarcate the vertical resistivity distribution. The geomorphological study reveals that the APSP campus falls on 

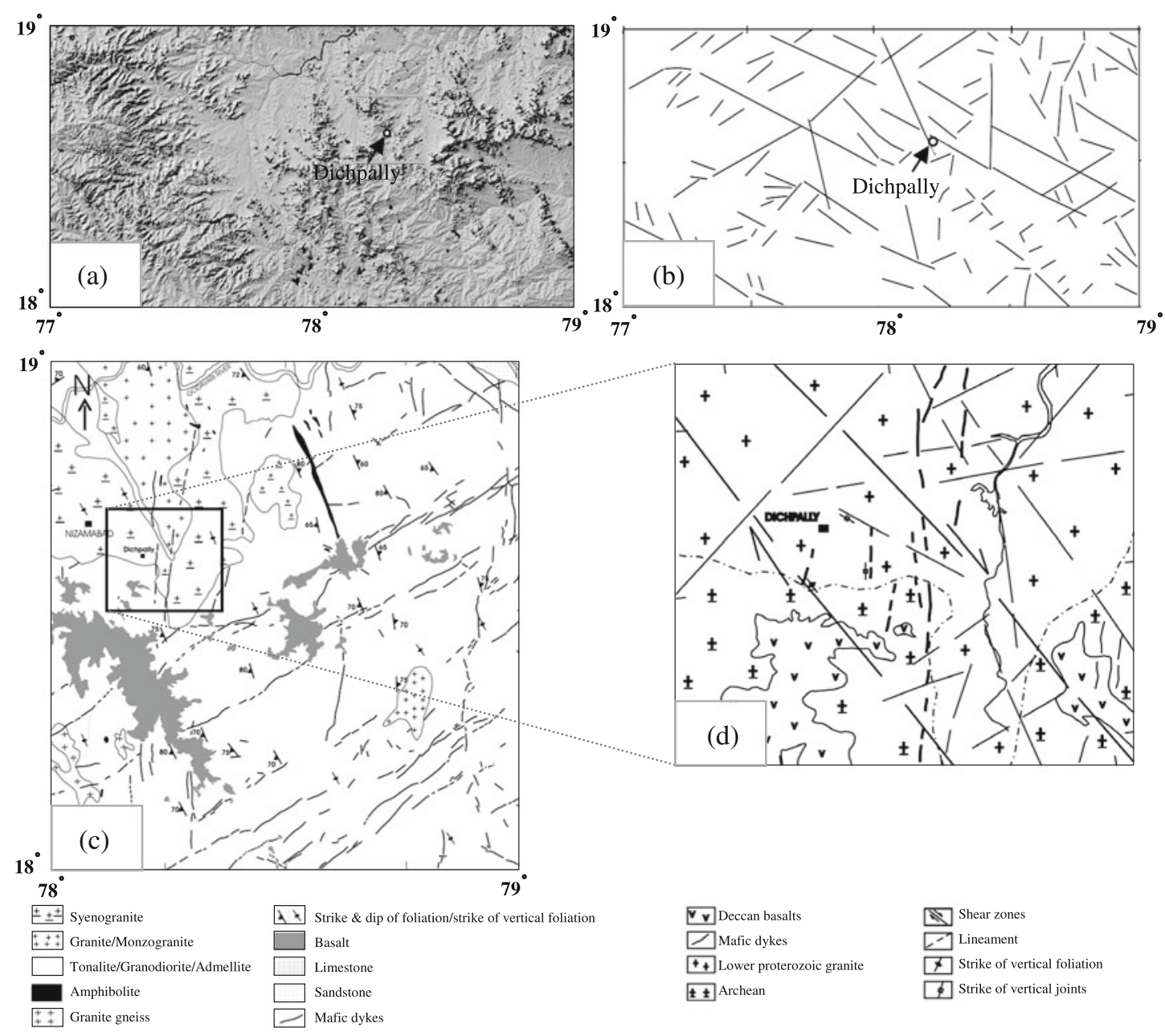

Figure 3. (a) SRTM; (b) interpreted lineament map from SRTM; (c) geological map; and (d) interpreted lineament from geological map of the study area and its surroundings.

a shear zone lineament, and hence, 1-D soundings are vulnerable to the near surface inhomogeneity (NSI) effects that mislead the resistivity interpretation (Chandra et al. 2004). Therefore, $2 \mathrm{D}$ electrical resistivity measurements were carried out to get the high resolution data. Four 2-D ERT profiles (ER1, ER2, ER3 and ER4) with Wenner-Schlumberger were carried out in and around the campus to investigate deep weatheredfissured/fractured granite associated with lineament. The profiles are $470 \mathrm{~m}$ long except ER2, i.e., $710 \mathrm{~m}$ long. The acquired data has been inverted by RES2DINV inversion program (Loke and Barker 1996; Loke 2000). The inverted resistivity images are arranged as per their layout in figure 4. Although the profiles ER1 and ER3 did not give any expected response to lineament, a little indication of low resistivity anomaly (marked by arrow at $360 \mathrm{~m}$ on lateral scale in figure 4) was observed in ER2. Chandra et al. (2010) studied ERT response of lineament for varying field conditions and noise levels and shown that such poor resistivity anomaly could also be the result of random noise in the field data. Still it cannot be ignored completely as the anomaly lies at the centre of the profile, which is high sensitive zone of the Wenner-Schlumberger array. However, it needs further detailed investigation to the deeper level. The profile ER4 lying outside the campus has given significant anomalous low resistivity zone at $265 \mathrm{~m}$ lateral scale. A line joining to these points found oriented in NW-SE direction corresponding to the major lineament as shear zone marked in lineament map and geological map of Nizamabad. Although, ER4 has reflected higher degree of anomaly, it lies outside the campus. The objective was to provide deep groundwater potential well inside the campus and hence, in spite of poor indication in ER2 image that falls inside the campus, was selected for deeper subsurface investigation, with the help of pole-pole ERT of $10 \mathrm{~m}$ electrode spacing using Syscal pro 72 instrument. 


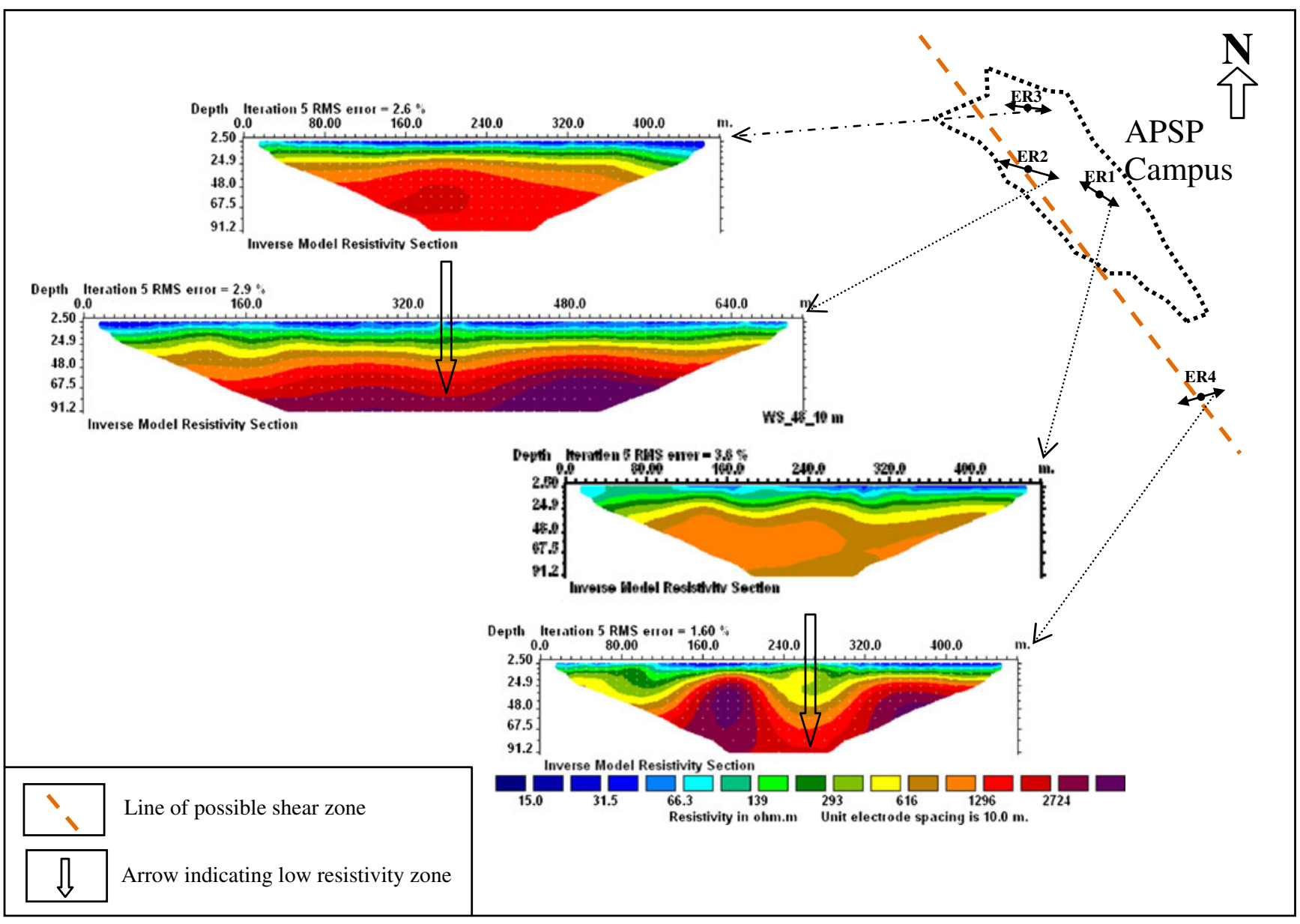

Figure 4. Wenner-Schlumberger ERT profiles at APSP campus and its vicinity and line of probable shear zone.

In pole-pole array, two electrodes (one current ' $\mathrm{B}$ ' and one potential ' $\mathrm{N}$ ') need to be planted at infinity distance called as remote electrodes, and other two electrodes (i.e., current 'A' and potential ' $M$ ') take part in the measurement along the profile (figure 5a) called active electrodes. It is not always possible to maintain the ideal infinity distance to the remote electrodes due to various reasons such as topographic undulations, busy road/rail tracks, forests, villages, cattle, etc. As the study area is of triangular in shape and surrounded by roads and rail track, arranging the remote electrodes at far off distance is not possible. In such situation, the placement effect of the remote electrodes on the apparent resistivity was studied.

Two arrangements of pole-pole array have been considered here, viz., (1) collinear pole-pole, where the remote electrodes are planted in the line of profile, and (2) transverse pole-pole, where remote current and potential electrodes are planted in transverse direction on either side of the profile line (figure 5).

For the $\Delta V$ potential difference $(\mathrm{mV})$ measured due to current injection ' $I$ ' $(\mathrm{mA})$, the apparent resistivity $\rho_{a}$ for half space can be calculated using equation (1) given below:

$$
\rho_{a}=K \frac{\Delta V}{I}
$$

where $K$ is called as geometrical factor that is determined solely by the geometry of the electrode set-up and can be calculated as:

$$
K=2 \pi\left[\frac{1}{|\mathrm{AM}|}-\frac{1}{|\mathrm{BM}|}-\frac{1}{|\mathrm{AN}|}+\frac{1}{|\mathrm{BM}|}\right]^{-1} \text {. }
$$

Using the above formula, geometrical factor $K_{c}$ and $K_{t}$ respectively for collinear and transverse polepole arrays can be formulated as per figure 5(a):

$$
\begin{gathered}
K_{c}=2 \pi a \frac{n^{2}-1}{n^{2}-n-4} \\
K_{t}=2 \pi a\left[1-\frac{1}{2 n}-\frac{1}{\sqrt{1+n^{2}}}\right]^{-1}
\end{gathered}
$$

where ' $a$ ' is the distance between active electrodes AM and ' $n a$ ' is the distance of the remote 
Collinear pole-pole

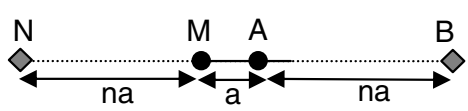

Active electrodes

$\triangle$ Remote electrodes

(a)

Transverse pole-pole

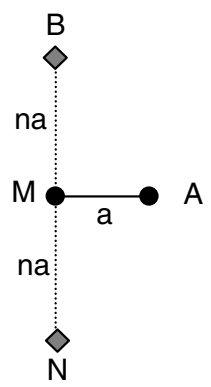

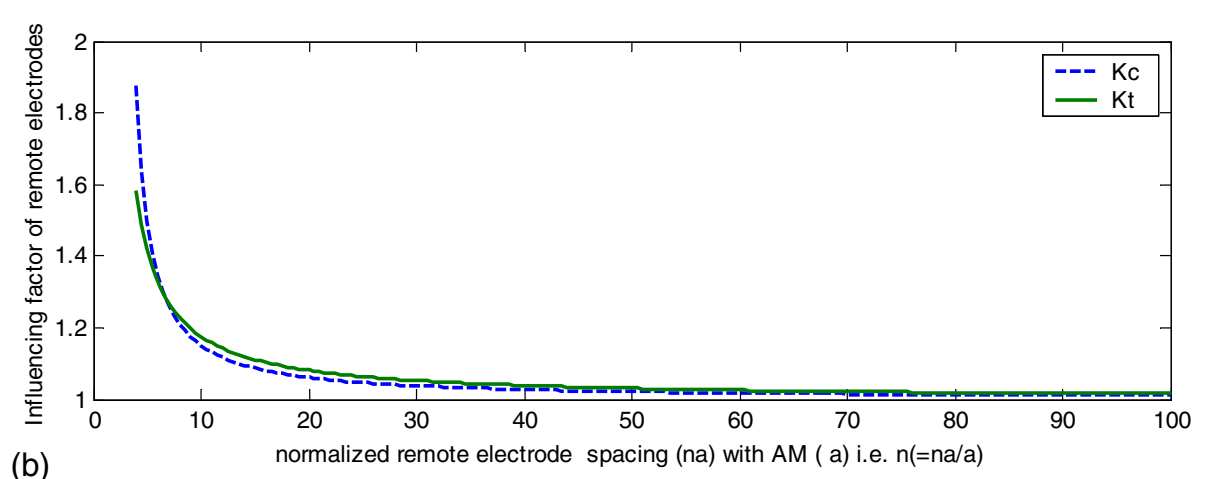

(b)

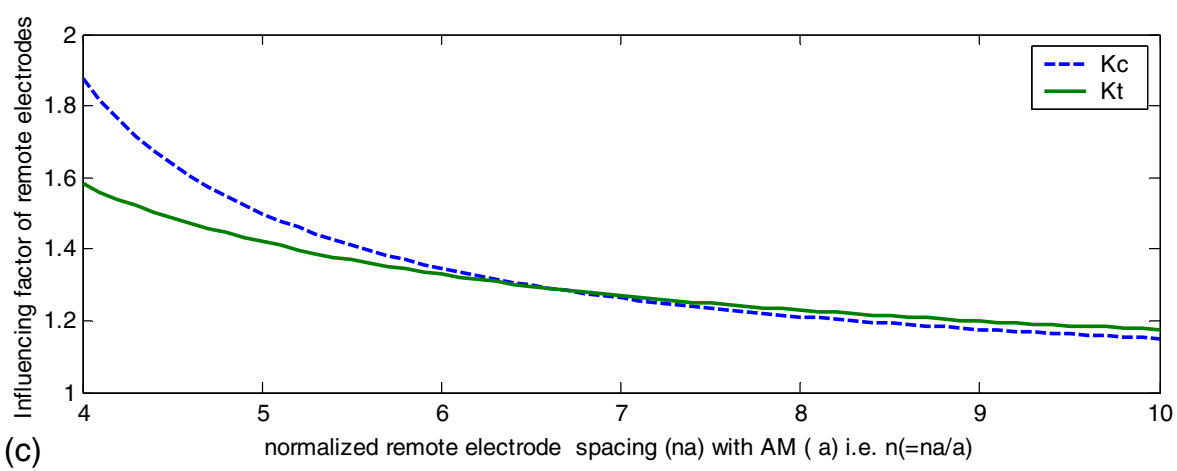

Figure 5. (a) Collinear and transverse pole-pole arrays, (b) influencing factor of remote electrodes on apparent resistivity measurement against normalized remote electrode spacing with active electrode spacing AM, and (c) zoom view of (b) for the $n$ in the range of $4-10$.

electrodes from $M$. The array become ideal polepole when $n$ is extremely large for which the above geometrical factor reduces to:

$$
K_{\infty}=2 \pi a .
$$

In this condition, it is immaterial which direction the remote electrodes are planted, the apparent resistivity measurement is unaffected.

To visualize the effect of the collinear and transverse pole-pole arrays on the apparent resistivity, the geometrical factor has been calculated with varying distance of remote electrodes. Figure 5(b) shows the computed geometrical factors $\left(K_{c}\right.$ and $K_{t}$ ) for collinear and transverse pole-pole arrays normalized with $K_{\infty}$ plotted against $n$, i.e., remote electrode spacing (BM) normalized with the active electrodes spacing (AM). The effect of remote electrode reduces exponentially with increasing value of $n$ and more or less become constant after $n$ reaches 10 or more. Therefore, it is universally adopted to keep remote electrode at least 10 times of the profile length for 1-D or largest value of AM in case of 2-D survey. Thus for $300 \mathrm{~m}$ long profile, remote electrodes are to be planted each at $3 \mathrm{~km}$ away that means total $6 \mathrm{~km}$ long wire has to be spread out solely for remote electrodes. But the problem was difficult even to maintain 10 times far distance to the remote electrodes and hence looking for small value of $n$, a clear difference can be seen between the $K_{c}$ and $K_{t}$ (figure $5 \mathrm{c}$ ). The $K_{t}$ has lesser effect than the $K_{c}$. For example, $K_{c}$ and $K_{t}$ reach to 1.42 and 1.55 respectively for $n=5$. 
Therefore in the present field, transverse pole-pole ERT was planned with remote electrode position 5 times (i.e., $\sim 1500 \mathrm{~m}$ ) of the largest value of $\mathrm{AM}$, i.e., $300 \mathrm{~m}$.

Due to the existing field constraints, the remote electrodes distance was compromised to 5 times instead of 10, correction factor (C.F.) was computed (i.e., C.F. $=K_{t} / K_{\infty}$ ) to overcome the effect of remote electrodes on the apparent resistivity. Figure 6(a) demonstrate the computed correction factor curve with varying electrode separation (AM) keeping the remote electrodes at varying distances, viz., 500, 525, 550, 600, 750, 1000, 1500, 2500, 4500 and $7500 \mathrm{~m}$. For each curve, position of the remote electrodes is fixed. Closer the remote electrodes, higher the degree of influence on apparent resistivity and hence higher the correction factor which is quite obvious. Thus the pole-pole
ERT were processed by incorporating the remote electrodes location and inverted to get the actual formation resistivity distribution.

The pole-pole ERT has revealed subsurface electrical resistivity response up to $285 \mathrm{~m}$ depth (figure 6b). The central low resistivity anomaly observed in the Wenner-Schlumberger image was well resolved, which is significantly low in the range of 300-500 $\Omega \mathrm{m}$ continuing to the bottom of the profile. High RMS error (i.e., 9.7) was expected due to laterally heterogeneous media, but the low resistivity anomaly of the order of $100 \Omega \mathrm{m}$ observed on the bottom edges was surprising. Therefore, the inverted data was checked for sensitivity distribution that is found in the range of $0.0785-19.4$ and hence applying the cut-off sensitivity 0.125 , low sensitive part was removed (figure 6c). Now the high sensitive resistivity section was found up to (a)
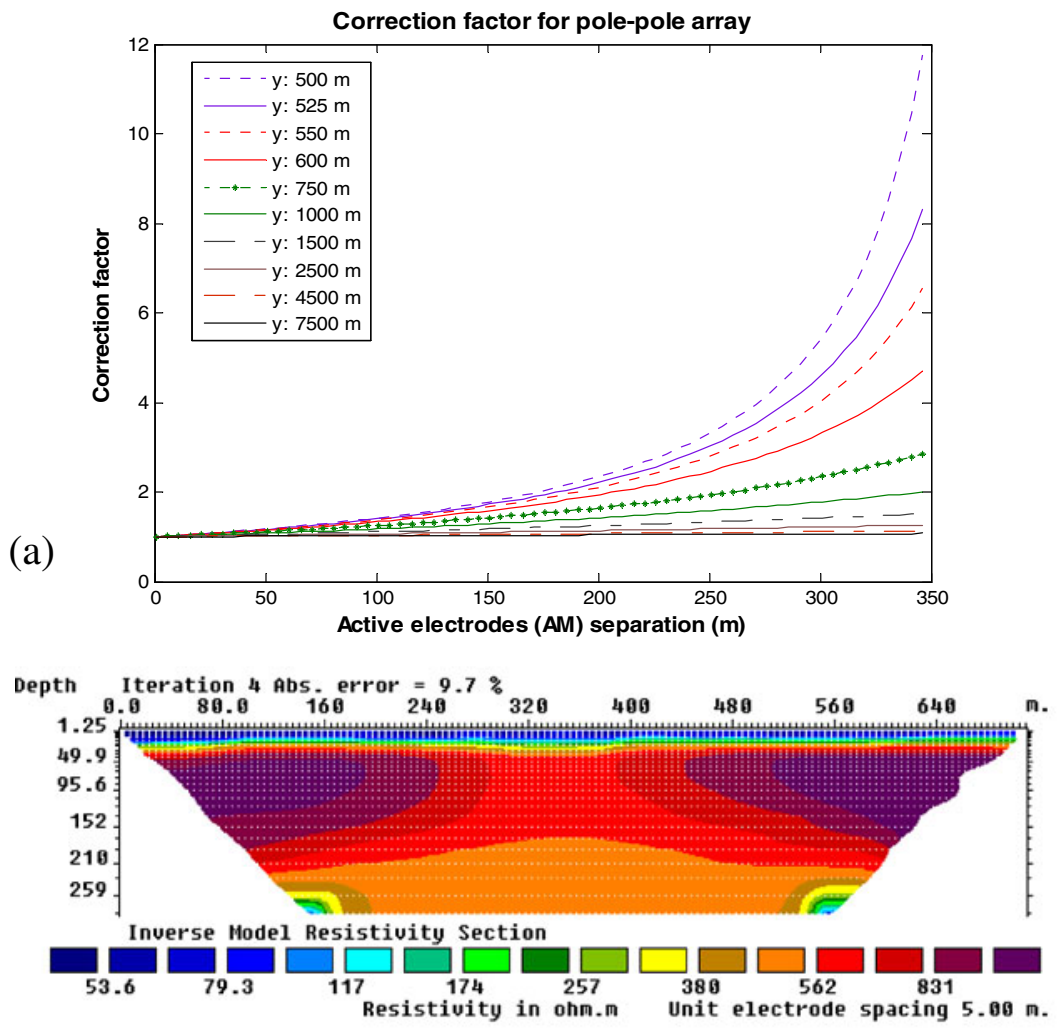

Recommended site for

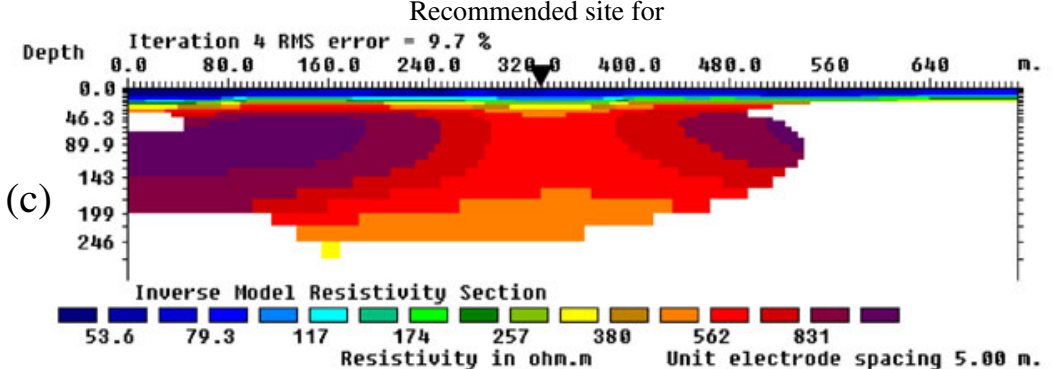

Resistivity Logging (NB-1)

Resistivity (ohm.m)

$\begin{array}{llll}0 & 10,000 \quad 20,000 \quad 30,000\end{array}$

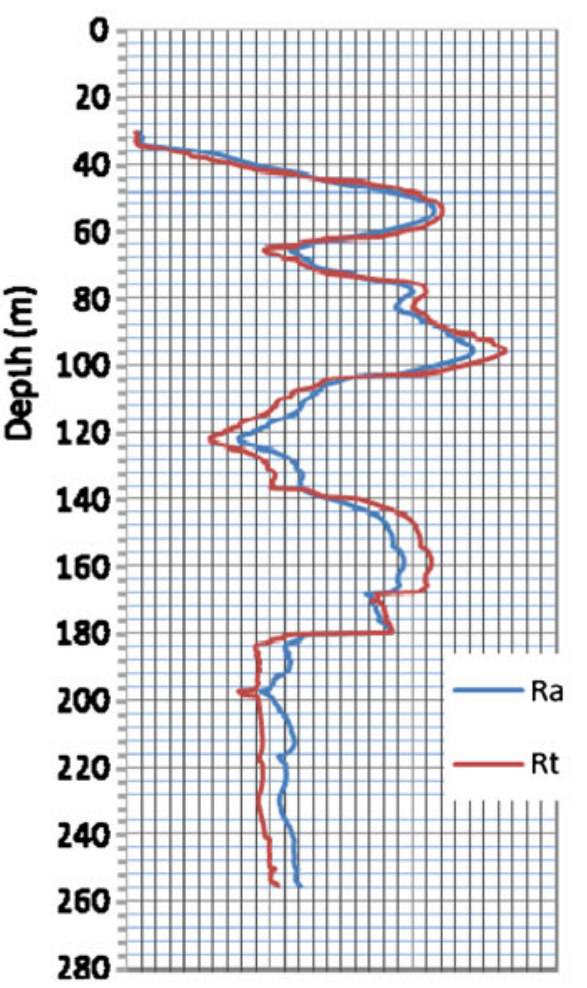

(d)

Figure 6. (a) Correction factor curve computed for varying positions of the remote electrodes, (b) transverse pole-pole ERT section, and (c) transverse pole-pole ERT section after blanking out the low sensitive zone. 
$240 \mathrm{~m}$ depth, where one can rely and take the decision.

As the electrolytic conduction is mainly responsible for current flow in granite, the low resistivity is an indication of weaker, i.e., weathered-fractured zone saturated with water. Such thick and deep anomalous zone is considered as an indication of deep tectonic fractures saturated with water and hence recommended for drilling of the deep well at the centre of ER2 profile.

\section{Validation}

To validate the above results, a well (NB-1) has been drilled at the recommended site down to a depth of $270 \mathrm{~m}$, where number of fracture zone has been encountered at different depths with the ingress of water at $\sim 31,110$, and $180 \mathrm{~m}$ respectively. Drilling authority reported occurrence of enormous amount of water yielding around $\sim 15 \mathrm{~m}^{3} / \mathrm{h}$ and hence drilling was stopped at $270 \mathrm{~m}$. A motor has been installed at $225 \mathrm{~m}$ depth to exploit the groundwater for drinking purposes. The bore well is supplying the water with the same yield since 2008. The well was logged for electrical resistivity measurement that has confirmed the water ingress depths in the form of low resistivity (figure $6 \mathrm{~d}$ ). There is an additional low resistivity zone encountered at $\sim 67 \mathrm{~m}$ depth indicating a thin sheet joint. Further validation was carried out by analyzing the temporal hydro-chemical distribution of pumped groundwater and synthetic simulation of ERT response of shear zone lineament.

\subsection{Hydrochemical analysis}

The mechanism of groundwater flow in fractured hard rocks, where inhomogeneties and discontinuities have a dominant role to play, is as important as that siting a well. Yield of a bore well in the multi-fracture system is depending on the individual fracture thickness, its water source and inter-communication, between the different fracture systems. To understand the aquifer inter-communication, hydrochemical and isotopic methods are quite useful (Mazor 1991; Sukhija et al. 2006).

Geomorphological and geosynthetic methods adopted in the study area resulted drilling of $270 \mathrm{~m}$ deep bore well with existence of three groundwater potential fracture zones. In order to find out its interconnectivity, hydrochemical analysis and C-14 dating were attempted. Apart from the drilled deep well (NB-1), two more samples were also collected for hydrochemistry and C-14 dating from the nearby existing shallow bore wells $(\sim 67 \mathrm{~m})$ (i.e., PB-2 at $\sim 25 \mathrm{~m}$ and PB-3 at $\sim 300 \mathrm{~m}$ distance)

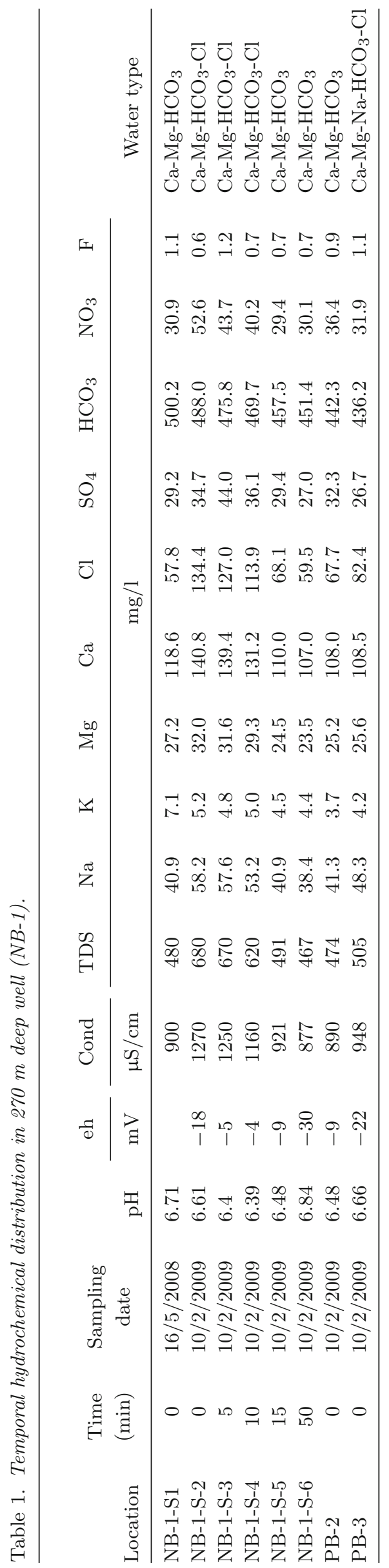


to understand the communication between shallow and deep aquifers.

Initially, one sample was collected from the newly drilled bore well using a simple bailor for hydrochemical measurements 10 days after the drilling. A 17.5 HP submersible pump was installed in the well at a depth of $225 \mathrm{~m}$ and has been pumped continuously for their use. The pump was stopped for few days before the C-14 sample collection. At the time of $\mathrm{C}-14$ sample collection, as soon as the pump started, a sample is collected for hydrochemistry and four more samples were collected at different intervals during the $50 \mathrm{~min}$. of pumping (table 1). For carbon-14 dating 150 ltr sample collected after $\sim 10 \mathrm{~min}$. of pump started.

Hydrochemical analysis (major ions including $\mathrm{pH}$, conductivity and TDS) and C-14 dating were made at NGRI Laboratory. The hydrochemical data provided some useful information on interconnectivity of different fractures. As it can be seen from table 1 , the concentration of different chemical constituents are having great difference when the sample was bailed out from the water table 10 days after the drilling and the 1st sample collected from the deep aquifer by submersible pump (table 1). The first sample is relatively more mineralized $(\sim 1.5$ times $)$ than the shallow well waters. The total dissolved solids (TDS) of deeper water is $680 \mathrm{mg} / \mathrm{l}$ and the shallow water (sample collected with the bailor) is only $480 \mathrm{mg} / \mathrm{l}$. Sodium concentration also maintain the same ratio as that of TDS, but calcium (Ca) and magnisium (Mg) concentrations are having lesser variation between deep and shallow waters. Deeper water has very high chloride concentration (134 mg/l) in comparison to shallow groundwater $(60-80 \mathrm{mg} / \mathrm{l})$ and the bicarbonate is almost same in shallow and deep groundwater. Shallow aquifer water type is $\mathrm{Ca}-\mathrm{Mg}-$ $\mathrm{HCO}_{3}$ and the deeper water type is $\mathrm{Ca}-\mathrm{Mg}-\mathrm{HCO}_{3}-$ $\mathrm{Cl}$. However, the concentration of different chemical constituents reduced gradually with in $50 \mathrm{~min}$. of pumping and reached to the levels of shallow aquifer/shallow wells nearby (figure 7 ).

The first sample at zero time (immediately after switching on the pump) represents the deeper zone water, i.e., the water around the pump at a depth of $230 \mathrm{~m}$. Since the deeper fracture groundwater yield is lesser than the pumping rate, with time, pump captured more water from the shallow zone. This capture is through inter-connectivity of different fracture systems and also directly through the well. Due to this, hydrochemistry of the pumping water changed gradually and reached to same as that of shallow water. Presence of more nitrate in deeper water than the shallow water indicates that the deeper fracture also connected to top
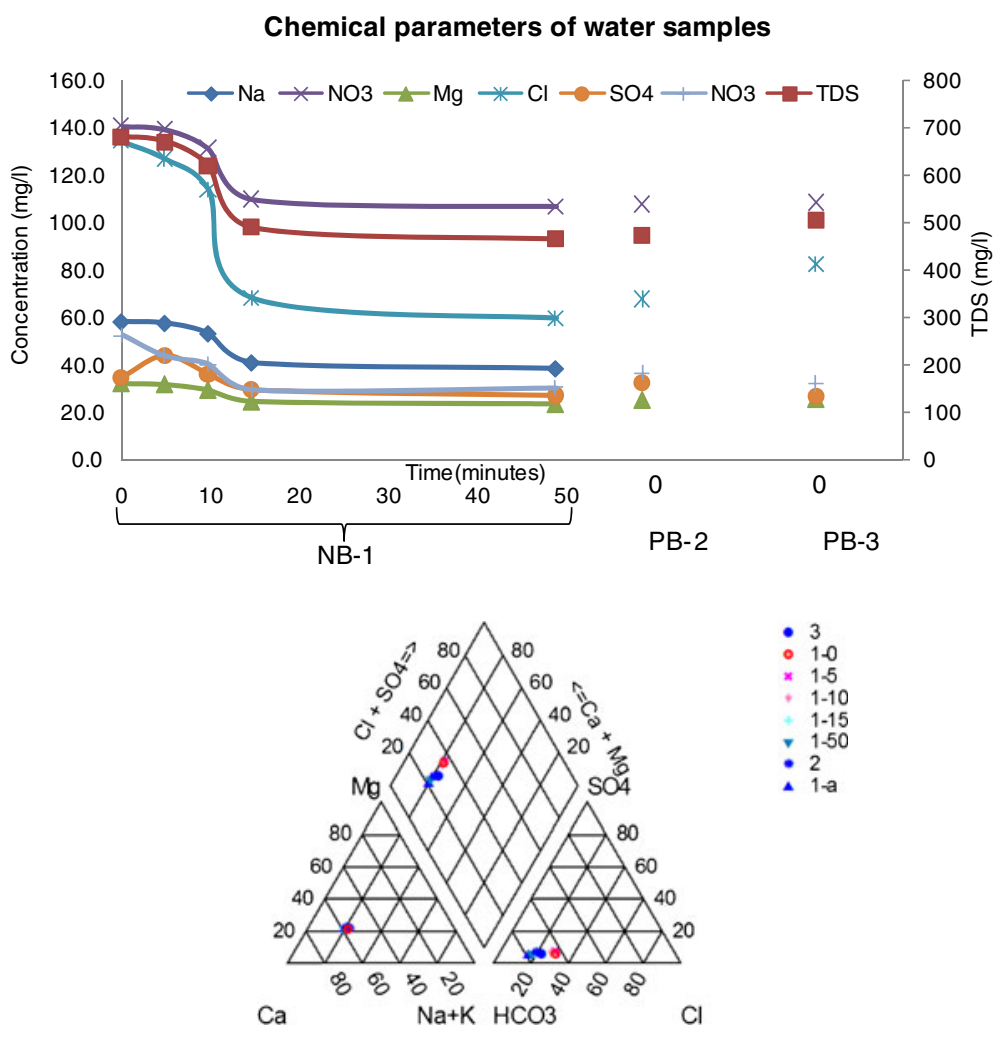

Figure 7. Temporal hydrochemical parameters of NB-1 $270 \mathrm{~m}$ deep and PB-2 and PB-3 surrounding shallow ( $\sim 60 \mathrm{~m})$ wells. 
shallow fractures/vadose zone in the nearby area. The C-14 results of the deep as well as shallow wells indicated only Modern age (about 50 years). These two observations indicate that though the deep well encountered multilayer aquifer system (sheet joints), being the shear zone, the sheet joints are connected by a network of vertical joints.

\subsection{Synthetic 2D resistivity modelling}

Although, all the observations have been found corroborating with each other, a little difference or some additional information was given by different approaches such as the resistivity response in ER2 Wenner-Schlumberger image was confined to shallow level (i.e., $91 \mathrm{~m}$ ) with little indication of lineament, whereas transverse pole-pole ERT has strongly reflected lineament with an indication of second weak (aquifer-II) zone below $80 \mathrm{~m}$ depth continuing to $240 \mathrm{~m}$ with high resolution data. Drilling results show encountering of the fractures with water ingress at 31, 110 and $180 \mathrm{~m}$ depth. Thus the second aquifer derived from ERT got subdivided into two fractured zones (i.e., subaquifers). Hydrochemical analysis indicates that, in spite of being three different fracture systems, they get inter-connected due to leakage through few cracks/joints in the basement rock at the time of pumping. Therefore it was decided to do a synthetic simulation incorporating all the possible scenario observed above and analyze the 2D electrical response.

A $470 \mathrm{~m}$ long and $290 \mathrm{~m}$ deep 2D synthetic model was prepared representing the actual field conditions. The $2 \mathrm{D}$ model has been divided into 2632 blocks of equal breadth $(2.5 \mathrm{~m})$ but varying height. The blocks were assigned resistivity values

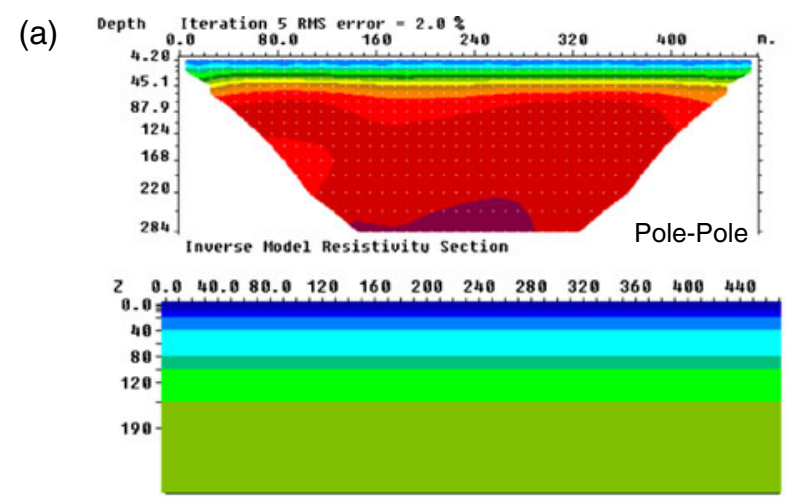

(b)
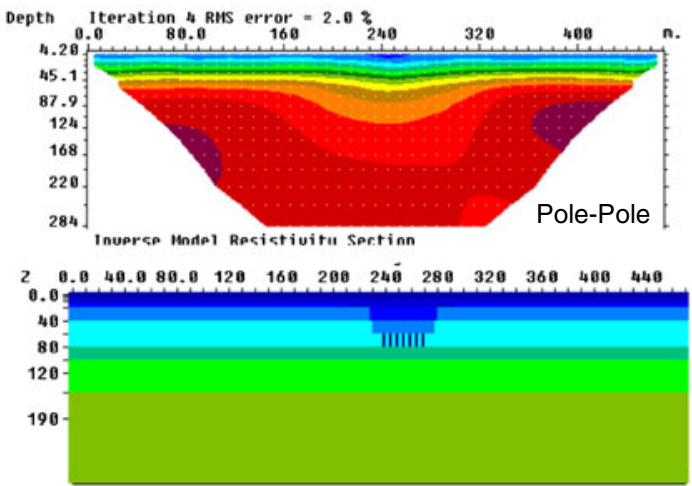

\section{Colour Index of Inverse Resistivity Section}

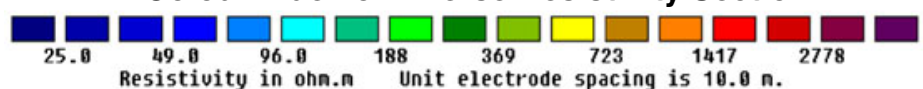

Colour Index of subsurface physical Resistivity Model

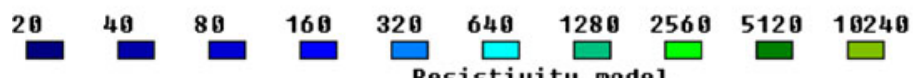

(c)
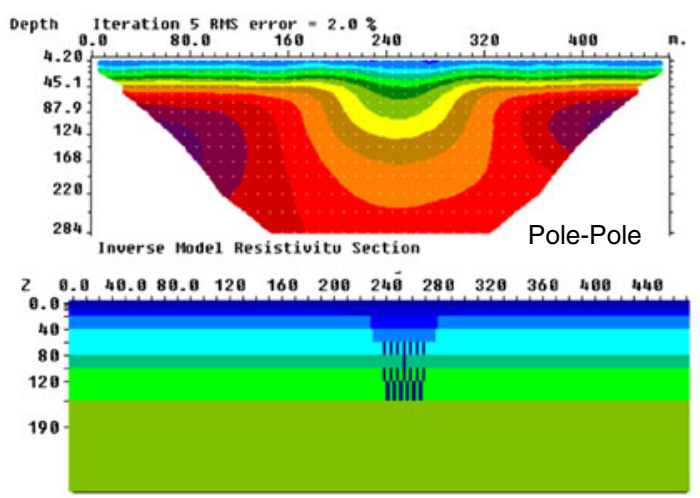

(d)
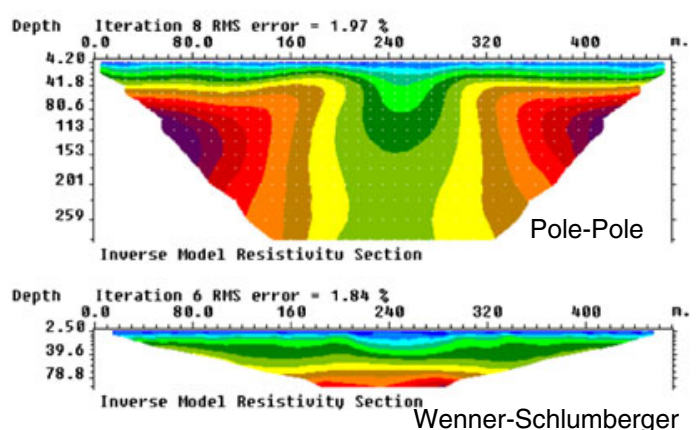

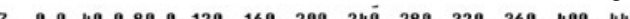

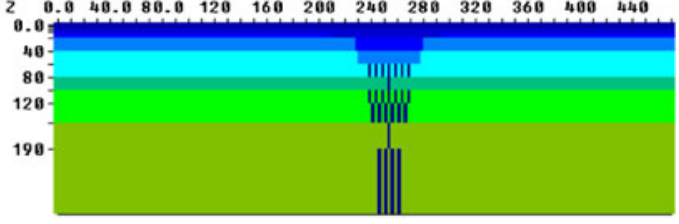

Figure 8. Synthetic ERT simulations for: (a) tabular/layered 2D model with increasing resistivity with depth, (b) central conductive zone representing $60 \mathrm{~m}$ deep weathered and $20 \mathrm{~m}$ underlying fissured/fractured granite in layered 2D model; (c) central conductive zone with increased fissured column down to $150 \mathrm{~m}$ depth; and (d) increasing the fracture column down to depth of $270 \mathrm{~m}$. 
in increasing order with depth considering the alteration in the granite reduces with depth resulting in reduction of volumetric percentage of water which causes rise in resistivity. Although number of synthetic simulations were performed, only four typical models are presented in figure 8, i.e., (i) horizontal stratified subsurface with increasing resistivity with depth; (ii) horizontal stratified subsurface with $80 \mathrm{~m}$ deep central low resistivity blocks; (iii) horizontal stratified subsurface with $150 \mathrm{~m}$ deep central low resistivity blocks; and (iv) horizontal stratified subsurface with $270 \mathrm{~m}$ central low resistivity blocks. The central blocks were assigned $20 \Omega \mathrm{m}$ resistivity to represent water saturated pores found due to fractures. Apparent resistivity data were generated for Wenner-Schlumberger and pole-pole arrays using RES2DMOD and produced true resistivity subsurface model after inversion of apparent resistivity data by RES2DINV. Prior to inversion, $2 \%$ random error was added to the apparent resistivity data to bring the simulation results to the real field conditions.

The first inverted true resistivity model has produced almost similar layered 2D resistivity structure as well as same order of resistivity to the synthetic subsurface model. As the depth level of the low resistivity blocks are increasing in second, third and fourth synthetic models, lowering of the low resistivity front could also be seen in the inverted resistivity models of the corresponding profiles. Figure 8(d) represents both the WennerSchlumberger and pole-pole images for the same synthetic model. The inverted 2D synthetic sections are reasonably close to the field sections.

It is important to note that, even the shallow low resistivity blocks produce the low resistivity anomaly to the greater depths than the actual. For example, low resistivity blocks assigned up to $80 \mathrm{~m}$ and $150 \mathrm{~m}$ in figure $8(\mathrm{~b}$ and $\mathrm{c})$ respectively were given relatively significant anomaly to the corresponding depth. But anomaly pattern (with less contrast) also continue roughly to its double the actual depth level. Thus, a care should be taken while considering the depth of the geological target and hence suggested to look for the significantly strong anomaly.

Thus, the investigation results obtained from the various methods are validated and the synthetic model in figure $8(d)$ can be taken as quite close to real subsurface condition. Although the present data is not sufficient to prepare actual weathering cross section, but to visualize ground condition, all the observations are integrated and prepared 2D cross section of weathering profile of the shear zone that shows top saprolite followed by underlying weathered-fissured, fissured and compact granite (figure 9). The central zone with dense fractures is nothing but the shear zones and the fracture zone demarcated through geophysics and conformed by drilling can be seen at different depths.

The integrated study has helped in exploring a deep potential groundwater zone in APSP campus falling in water scarce granitic terrain in Nizamabad district, Andhra Pradesh (India). It

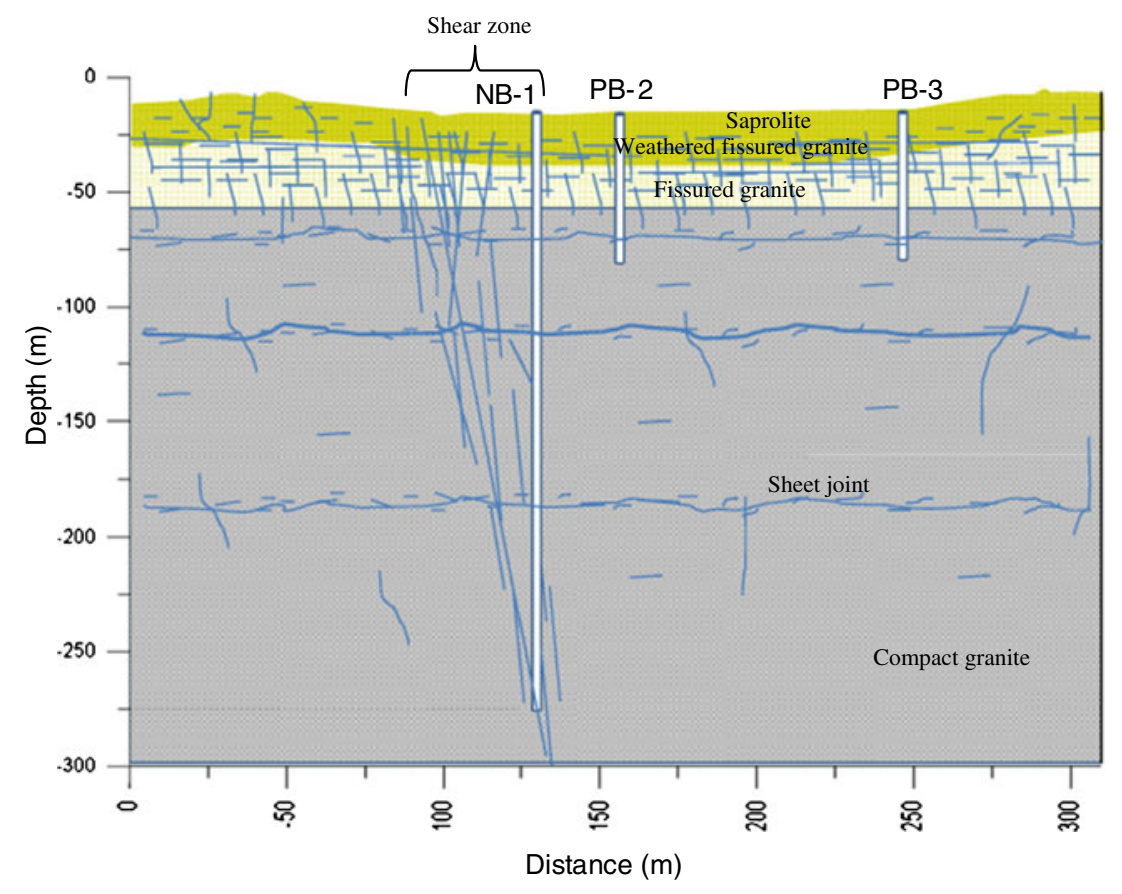

Figure 9. 2D profile of weathering cross section of shear zone prepared based on the investigations. 
has shown the existence of multi-aquifer set-up associated with lineament in granitic hard rock terrain.

\section{Summary and conclusion}

In the present study, groundwater potential zone at much deeper level was investigated using integrated geomorphological and geophysical investigations. The deep aquifer system appears to have multi-fractured zones with higher permeability than usually expected. As the area experienced several tectonic events and is associated with Godavari rift valley, it is supposed to create a wide shear zone.

The geomorphology played an important role in selecting suitable sites for carrying out deep geophysical surveys with high degree of chances to meet the objective. Brittle deformation features are water bearing and are associated with the formation of deep open cavities that enhance the permeability of the country rocks. The studies suggest that the structures having a NW-SE strike direction are more likely to be under extension and therefore open, hence they are the primary hydrogeological targets.

Integrating all the factors, such as, the study area is the part of the NW-SE trending shear zone, SW fringe of the Godavari rift zone, major lineament traversing in NW-SE as well as conductive thick zone obtained at deeper level; the site was considered favourable for deep water potential zone and was recommended for drilling. The $270 \mathrm{~m}$ deep drilling confirmed the geophysical anomalies. A multi-aquifer system with two deep thick tectonic fracture zones at $\sim 110$ and $180 \mathrm{~m}$ depths are first time encountered. Interconnectivity of different water bearing zones validated through change in hydrochemical concentration during the pumping.

The study also demonstrated that the transverse pole-pole array is preferable over the collinear pole-pole array where remote electrodes are difficult to plant at sufficiently far distance. The previous array has lesser influence compared to later one on the apparent resistivity measurement.

Although the geophysical, drilling and hydrochemical results revealed either little different or some additional information, the synthetic simulation incorporating all the information produce quite close response to the field ERT. Hence the field ERT supported the existence of the multiaquifer system composed of fractures in the granitic terrain at Nizamabad. Synthetic simulation study also alerts that the depth of the hydogeological target should be carefully decided based on the resistivity anomaly. The anomalous pattern is roughly seen continuing double the depth of the hydrogeological target in pole-pole ERT with weaker anomaly below the target depth.

The integrated approach has finally helped in exploring deep thick fracture zones in granitic terrain at Nizamabad district in Andhra Pradesh. This is a potential aquifer, which is yielding copious water to fulfill the groundwater demand of APSP campus.

\section{Acknowledgements}

The authors acknowledge the support provided by the Director, NGRI, Hyderabad to carry out this work. They are also thankful to Andhra Pradesh Special Police, 7th Battalion, Dichpally, Nizamabad for the financial and logistic support to carry out this study. Special thanks to APSP officers Sri T Vijay Kumar, Executive Engineer, Sri V Ravi Kumar, Deputy Executive Engineers, Sri Srinivas and Sri Devender, Assistant Engineers for taking the extra care. Help extended by Dr Dewashish Kumar, Mr T Yellappa, NGRI in data collection and their valuable suggestions in preparing the manuscript are greatly acknowledged. The constructive comments and suggestions by anonymous reviewers are greatly appreciated, which has tremendously improved the quality of the paper.

\section{References}

Acworth R I 1987 The development of crystalline basement aquifers in a tropical environment; Quart. J. Eng. Geol. 20 265-272.

Barker R, Rao T V and Thangarajan M 2001 Delineation of contaminant zone through electrical imaging technique; Curr. Sci. 81(3) 277-283.

Chand R, Chandra S, Rao V A and Jain S C 2004 Estimation of natural recharge and its dependency on sub-surface geoelectric parameters; J. Hydrol. 299 67-83.

Chandra S, Rao V A and Singh V S 2004 A combined approach of Schlumberger and axial pole-dipole configurations for groundwater exploration in hard rock areas; Curr. Sci. 86(10) 1437-1443.

Chandra S, Rao V A, Krishnamurthy N S, Dutta S and Ahmed S 2006a Integrated studies for characterization of lineaments to locate groundwater potential zones in hard rock region of Karnataka, India; Hydrogeol. J. 14 767-776.

Chandra S, Atal S, Murthy N S K, Subrahmanyam K, Rangarajan R, Reddy D V, Nagbhushanam P, Murthy J V S, Ahmed S and Dimri V P 2006b Oozing of water in parts of Andhra Pradesh, India; Curr. Sci. 90 1555-1560.

Chandra S, Atal S, Reddy D V, Nagabhushanam P, Murthy N S K, Subrahmanyam K, Rangarajan R, Ahmed S and Dimri V P 2006c Explication of water sprouting phenomenon observed in parts of Andhra Pradesh; J. Geol. Soc. India 68 157-159.

Chandra S, Ahmed S, Ram A and Dewandel B 2008 Estimation of hard rock aquifers hydraulic conductivity from geoelectrical measurements: A theoretical development with field application. J. Hydrol. 35 218-227.

Chandra S, Dewandel B, Dutta S and Ahmed S 2010 Geophysical model of geological discontinuities in a granitic 
aquifer: Analyzing small scale variability of electrical resistivity for groundwater occurrences; J. Appl. Geophys. 71 137-148.

Chigira M 2001 Micro-sheeting of granite and its relationship with landsliding specially after the heavy rainstorm in June 1999, Hiroshima Prefecture; Japan Eng. Geol. 59 219-231.

Dewandel B, Gandolfi J-M, Zaidi F K, Ahmed S and Subrahmanyam K 2007 A decision support tool with variable agroclimatic scenarios for sustainable groundwater management in semi-arid hard rock areas; Curr. Sci. 92(8) 1093-1102.

Dewandel B, Lachassagne P, Wyns R, Maréchal J C and Krishnamurthy N S 2006 A generalized 3-D geological and hydrogeological conceptual model of granite aquifers controlled by single or multiphase weathering; J. Hydrol. 330 260-284.

Dhakate R, Singh V S, Negi B C, Chandra S and Rao V A 2008 Geomorphological and geophysical approach for locating favourable groundwater zones in granitic terrain, Andhra Pradesh, India; J. Environ. Manag. 88(4) 1373-1383.

Dubbak M M 1990 Groundwater resource and development potential of Nizamabad district, Andhra Pradesh, CGWB-SR Technical Report.

Eggler D H, Larson E E and Bradley W C 1969 Granites, gneisses and the Sherman erosion surface, Southern Laramie Range, Colorado, Wyoming; American J. Sci. $267510-522$.

Eswaran H and Bin W C 1978 A study of deep weathering profile on granite in peninsular Malaysia: I. Physicochemical and micromorphological properties; J. Soil Sci. Soc. America 42 144-149.

Houston J F T and Lewis R T 1988 Victoria province draught relief project, II. Borehole yield relationships; Ground Water 26 418-426.

Howard K W F, Hughes M, Charlesworth D L and Ngobi G 1992 Hydrogeologic evaluation of fracture hydraulic conductivity in crystalline basement aquifers of Uganda; Hydrogeol. J. 1 55-65.

Jain S C, Chand R, Rao V A, Chandra S, Prakash B A, Negi B C, Sharma M R K and Seth D P 2003 Evolution of cost effective and sustainable management schemes of water resources in Bairasagara Watershed, Kolar District, Karnataka, NGRI-2003-GW-391, 46p.

Keller G V and Frischknecht F C 1966 Electrical methods in geophysical prospecting; First edn, Pregamon Press Inc.

Kelly W E and Frohlich R K 1985 Relation between aquifer electrical and hydraulic properties; Ground Water 23(2) 182-189.

Krishnamurthy N S, Dutta S, Girard J F, Rao V A, Chandra S, Kumar D, Marc D, Gouez J M, Baltasat J M, Dewandel B, Gandolfi J M, Voullamoz J M and Ahmed S 2006 Electrical resistivity tomography and magnetic resonance sounding studies for characterising the weathered-fractured aquifer in A.P., India, NGRI-2006GW-529.

Lattman L H and Parizek R R 1964 Relationship between fracture traces and the occurrence of groundwater in carbonate rocks; J. Hydrol. 2 73-91.
Ledger E B and Rowe M W 1980 Release of uranium from granitic rocks during in situ weathering and initial erosion (central Texas); Chem. Geol. 29 227-248.

Loke M H 2000 Electrical imaging surveys for environmental and engineering studies: A practical guide to 2-D and 3-D surveys, $67 \mathrm{p}$.

Loke M H and Barker R D 1996 Rapid least-squares inversion of apparent resistivity pseudosections by a quasiNewton method; Geophys. Pros. 44 131-152.

Mabee S B, Hardcastle K C and Wise D W 1994 A method for collecting and analyzing lineaments for regional scale fractured bed rock aquifer studies; Ground Water 32(6) 884-894.

Magowe M and Carr J R 1999 Relationship between lineaments and ground water occurrence in western Botswana; Ground Water 37 282-286.

Maréchal J C, Dewandel B, Subrahmanyam K and Torri R 2003 Review of specific methods for the evaluation of hydraulic properties in fractured hard-rock aquifers; Curr. Sci. 85(4) 511-516.

Mazor E 1991 Applied chemical and isotopic groundwater hydrology; Open University Press, Milton Keynes, UK, $274 \mathrm{p}$.

Perraju P and Natarajan V 1977 Peninsular gneiss in northern parts of A.P.; J. Geol. Soc. India 18(5).

Rao V A and Chandra S 2005 Delineation of aquifer geometry in Bairasagara watershed, Kolar District, Karnataka; J. Appl. Hydrol. xviii 66-73.

Rao V A, Kumar D, Chandra S, Nagaiah E, Kumar A, Ali S and Ahmed S 2008 High-resolution Electrical Resistivity Tomography (HERT) Survey for Groundwater Exploration at APSP Campus, Dichpally, Nizamabad district, Andhra Pradesh, Tech. Rep. No. NGRI-2008-GW-626.

Sarma B S P and Rao M V R K 2005 Basement structure of Godavari basin, India - geophysical modeling; Curr. Sci. 88(7) $1172-1174$.

Sharma A and Rajamani V 2000 Weathering of gneissic rocks in the upper reaches of Cauvery river, south India: Implications to neotectonics of the region; Chem. Geol. $166203-233$.

Singhal D C, Sri Niwas, Shakeel M and Adam B M 1998 Estimation of hydraulic characteristics of alluvial aquifer from electrical resistivity data; J. Geol. Soc. India $\mathbf{5 1}$ 461-470.

Solomon S and Quiel F 2006 Groundwater study using remote sensing and geographical information systems in the central highland of Eritrea; Hydrol. J. 14(6) 1029-1041.

Sukhija B S, Reddy D V, Nagbhushanam P, Bhattacharya S K, Jani R A and Kumar D 2006 Characterization of recharge processes and groundwater flow mechanism in weathered-fractured granites of Hyderabad (India) using isotopes; Hydrogeol. J. 14 663-674.

TERI's report 2003 TERISCOPE at http://www.teriin. org/teriscope/resupdates/oasis.htm

Wyns R, Baltassat M, Lachassagne P, Legchenko A, Vairon J and Mathieu F 2004 Application of SNMR soundings for groundwater reservoir mapping in weathered basement rocks (Brittany, France); Bull. Soc. Geol. Fr. 175(1) 21-34. 